\title{
Charles Tomes lecture addresses the 'trauma of trauma'
}

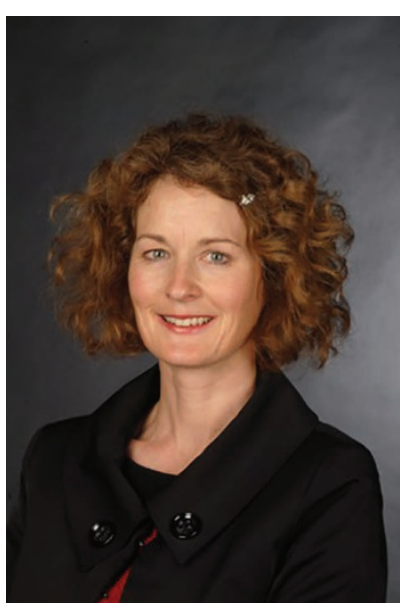

This year's prestigious Charles Tomes lecture at the Faculty of Dental Surgery of the Royal College of Surgeons was given by Professor Helen Rodd (pictured), who addressed the topic: 'The trauma of trauma: psychosocial impacts of dental injury in childhood.

Helen Rodd is Professor and Honorary Consultant in Paediatric Dentistry at the School of Clinical Dentistry, University of Sheffield.

Professor Rodd's overall message was that the psychosocial impact of both a dental injury and its treatment in childhood can be profound and much more could and should be done to help children recover from lost or broken teeth. There also needs to be more research to understand how children cope with injury and treatment.

Around 12\% of British 12-year-olds experience injury to one or more of their permanent incisors. Of that percentage, boys are likely to outnumber girls by $2: 1$. Meanwhile, $4 \%$ of 15 -year-olds who have an accident report that they fear their injury will be a lifelong burden.

Professor Rodd said: 'To date, we have been not at all good at including patient reported outcome measures in clinical trials. What value is a fabulous MTA apical barrier if the patient's evaluation of their own dental appearance and willingness to smile was not also sought as a core outcome?'

However, studies are starting to emerge relating to dental injury, including work being undertaken by Professor Rodd at the University of Sheffield. She is part of a multidisciplinary team which has built a reputation for giving children a voice in relation to their dental conditions.

Professor Rodd described her work and the innovative ways in which children are being invited to provide their thoughts and feelings, including the use of cognitive behavioural therapy (CBT).

'Above all - we need to listen carefully to our patients; many of them have a sense of worry and anxiety about treatment and the future of their tooth', said Professor Rodd.

An international expert panel, led by UK paediatric dentist Peter Day, is developing a research framework for any future trial involving trauma-related treatments. This will ensure that children's views will be heard, in outcomes that matter to them, such as anxiety and Oral Health Related quality of Life (OHRQoL).

\section{Joy Harrild Award for Young Dentists launched}

The British Dental Association (BDA) has launched the Joy Harrild Award for Young Dentists, aiming to recognise and celebrate outstanding young dentists in the profession. The Award is open for nominations for BDA member dentists (up to ten years' post-qualification) who have made a significant contribution to the profession.

The Award is named in honour of Joy Harrild, an inspirational young dentist and BDA Young Dentist

Committee member, whose life was tragically cut short by a car accident in 2016.

To be considered, nominees must meet at least two of the Award's criteria, including making a significant contribution to the profession, raising the profile of dentistry,

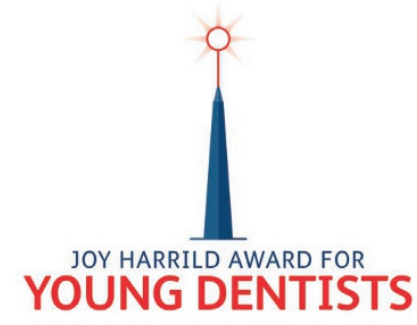
demonstrating an outstanding commitment to training and professional development, or making a contribution to the BDA, or the wider society.

The Award winner will be invited to receive their Award at the BDA's Honours and Awards ceremony, which will take place during the British Dental Conference and Exhibition 2018 in Manchester. To nominate a young dentist that you think is going above and beyond visit www.bda.org/youngdentistaward.

The deadline for nominations is $5 \mathrm{pm}$ on 17 May 2017. 